\title{
BIONECROPOLÍTICA NAS ÁREAS DE RESSACA EM MACAPÁ/AP
}

\author{
BIONECROPOLITICA IN THE AREAS OF \\ HANGOVER (WETLANDS) IN MACAPÁ / AP
}

\section{Bruno de Oliveira Rodrigues ${ }^{1}$ Wilson Madeira Filho'}

\begin{abstract}
RESUMO: Desenvolveremos neste trabalho, a partir das noções de Biopolítica de Michel Foucault e de Necropolítica de AchilleMbembe, analise sobre a configuração urbana que vem implicando na perpetuação e reprodução da pobreza das populações tradicionais nas áreas de ressacas (áreas úmidas) na cidade de Macapá/AP. Este processo é marcado pela utilização de mecanismos de demarcação territorial e controle, ratificadas por estruturas de hegemonia política que produzem searas de contenção, reprodução e geração de miséria que, encarcerados em delimitações territoriais restritas, são condicionados à subalternização de processos de dominação que constituem a organização sócio-política. Indica-se que a estética das referidas situações desenha dimensões de controle social e criam representações domesticadas que retroalimentam processos de constituição de uma identidade inferiorizada e negativada, a qual fortalece uma necropolítica colonizadora.
\end{abstract}

Palavras-chaves: Conflitos socioambientais; Necropolítica; Biopoder; Áreas de Ressaca; Controle Social.

\begin{abstract}
Wewilldevelop in thiswork, basedonthenotionsof Michel Foucault 's Biopolitica andNecropoliticaby AchilleMbembe, ananalysisoftheurbanconfigurationthathasbeenimplicated in theperpetuationandreproductionofthepovertyofthetraditionalpopulations in theareasofhangovers (wetlands) in thecityof Macapá / AP. Thisprocessismarkedbythe use ofmechanismsof territorial demarcationandcontrol, ratifiedbystructuresofpoliticalhegemonythatproduce searas ofcontainment, reproductionandmiserythat, imprisoned in restricted territorial delimitations, are conditionedtothesubalternizationof processes ofdominationthatconstitutethesocio-politicalorganization. It ispointed out thattheaestheticsofsuchsituationsdrawsdimensions of social controlandcreatedomesticatedrepresentationsthat feed back processes ofconstitutionofaninferiorizedandnegativedidentity, whichstrengthens a colonizingnecropolitica.
\end{abstract}

Keywords: Socio-environmentalconflicts; Necropolitica; Biopower; Surf Areas; Social Control.

\section{INTRODUÇÃO}

As cidades se apresentam enquanto fenômeno complexo, intermediando aglomerados urbanos e vazios colossais, onde se agitam ideologias, retóricas, especulações, contemplações, em dimensões fragmentárias, provindas de conhecimentos parcelares e desconexos (LEFEBVRE, 2001, p. 115). Não são, portanto, sistemas, mas sim subsistemas interconectados

${ }^{1}$ Professor da Universidade do Estado do Amapá (UEAP). Doutorando em Sociologia e Direito pela Universidade Federal Fluminense. Orcid: http://orcid.org/0000-0002-7156-938X

${ }^{2}$ Professor Titular da Faculdade de Direito e do Programa de Pós-Graduação em Sociologia e Direito da Universidade Federal Fluminense. Orcid: http://orcid.org/0000-0002-2322-7094 
com referência no modelo cidade-global, mas que produzem efeitos locais bastante próprios e específicos, pois configuram de maneira bastante particular as dimensões reais de produção e dimensão do espaço.

As cidades são obras efêmeras de um processo de transformação permanente de seus moradores que, num apogeu lúdico, (re)produzem processos de envelhecimento dos espaços e desaparecimento contínuo dos bens de consumo, ironicamente chamados de "duráveis" (LEFEBVRE, 2001, p. 133). Na crista dos debates sobre os problemas urbanos de moradia e de habitat se revelam processos de desenvolvimento econômico que não são acompanhados por processos de desenvolvimento social, fazendo velar a manutenção de uma estagnada configuração das relações sociais (LEFEBVRE, 2001, p. 137).

Os modelos de cidades se sobrepõem e são erigidas sobre as ruínas das cidades anteriores, sobrepostas por novos modelos a serem consumidos e, em um processo de transformação pela industrialização, as cidades passam de recipientes e espetáculos passivos para centros de decisão política, meio de produção e dispositivo de exploração social do trabalho (LEFEBVRE, 2001, p. 137).

No Brasil, desencadeiam-se processos urbanos de efeitos negativos, marcados pela degradação urbanístico-ambiental e pela exclusão territorial que atingem principalmente as camadas empobrecidas da sociedade. As terras mais urbanizadas e em melhores localizações (centros das cidades) foram reservadas para pessoas com mais prestigio, poder e influência, enquanto os demais foram empurrados para espaços mais distantes e precários. Estes espaços centrais passam, portanto, por processos de embelezamento e infraestrutura, recebendo grandes investimentos públicos para tais fins (RIBEIRO, 2013, p. 53). A globalização econômica apresenta uma nova geografia de centralidade e marginalidade (Ó CATÃO, 2015, p. 118).

Podemos dizer que as populações menos abastadas se abrigam às margens dos mananciais de abastecimento público, nas encostas dos morros, nas margens dos córregos ou, como em Macapá, sobre as áreas de ressacas. Todos estes locais são mais suscetíveis às intempéries da natureza, o que colocam a população à mercê de sua própria sorte. Em geral, no campo dos estudos relativos aos conflitos socioambientais, essas áreas têm sido designadas também como "zonas de sacrifício".

O presente estudo se posiciona num espaço de pensar a elaboração da cidade em seus efeitos colaterais, onde áreas de preservação permanente podem se encontrar presumidas enquanto zonas de sacrifício, recortando estudo de caso nas áreas de ressaca da cidade de Macapá/AP, onde a ocupação informal sobre áreas de alagado determinou o desenho urbano, a colocando enquanto um fértil objeto analítico.

\section{RESSACAS}

A cidade de Macapá, capital do Estado do Amapá, contava, de acordo com o IBGE, com cerca de 500 mil habitantes em agosto de 2018. Destes, estima-se que cerca de 90 mil pessoas residam em áreas de ressaca (IBGE, 2010).

No Amapá, zonas úmidas são localmente denominadas como "áreas de ressaca". Tratamse, em geral de áreas inundadas periodicamente pelas cheias do Rio Amazonas e seus afluentes. De acordo com o Plano Diretor da Cidade de Macapá, no $₫ 4^{\circ}$, art. $5^{\circ}$, são consideradas como reservatórios naturais de água, apresentando um ecossistema rico e singular e que so-

PRACS: Revista Eletrônica de Humanidades do Curso de Ciências Sociais da UNIFAP 
frem a influência das marés e das chuvas de forma temporária. São bacias inundáveis de maneira periódica e que servem como habitat para diversas espécies de plantas, peixes e anfíbios, mas que comportam a diversidade de um ecossistema frágil.

As ressacas trazem benefícios para a cidade, na medida em que, sendo zonas interligadas, servem como proteção contra enchentes e previnem à erosão, servindo como depósito de sedimentos. Como sofrem inundações, contribuem para o equilíbrio térmico da Cidade, auxiliando na regulação climática, controlando a temperatura local.

As áreas de ressaca detêm funcionalidade no meio ambiente, assim, o planejamento urbano deve ser operacionalizado de maneira a não causar impactos na interligação natural dessas zonas, as quais formam um único manancial, permitindo a equalização dos níveis das águas. Contudo, muitas dessas áreas inundáveis foram já isoladas pela ação antrópica ${ }^{3}$, principalmente pelo isolamento ocasionado pela construção de estradas.

No Estado do Amapá predomina-se o clima tropical superúmido, que varia conformeduas estações, inverno e verão. Na cidade de Macapá, de dezembro a junho, ocorrem chuvas de forma contínua e, os períodos considerados mais secos, com pouca incidência de chuva, ocorrem de setembro a novembro. De acordo com dados da Promotoria do Meio Ambiente do Estado do Amapá (2011), a temperatura média anual na cidade varia entre $26 \mathrm{C}^{\circ}$ a $35 \mathrm{C}^{\circ}$, com pluviosidade anual de $3250 \mathrm{~mm}$ (milímetros), sendo $250 \mathrm{~mm}$ por mês no período chuvoso.

Nestes ambientes, a interação antrópica causa impactos por vezes irreversíveis. Desta forma, as áreas de ressaca deveriam ser tratadas como áreas de proteção ambiental. A lei 9.985/2000, art. 15 considera Área de Proteção Ambiental (APA) uma área em geral extensa, com certo grau de ocupação humana, dotada de atributos abióticos, bióticos, estéticos ou culturais especialmente importantes para a qualidade de vida e o bem-estar das populações humanas, e tem como objetivos básicos proteger a diversidade biológica, disciplinar o processo de ocupação e assegurar a sustentabilidade do uso dos recursos naturais.

A partir de 2000, se intensificou no Munícipio de Macapá, através da Secretaria do Estado de Meio Ambiente (SEMA, 2008) e da Secretaria Municipal de Planejamento e Coordenação Geral (SEMPLA, 2004), a organização de estudo governamentais que viabilizasse estabelecer a importância das Áreas de Ressacas enquanto APAs, por meio do Zoneamento Ecológico Econômico Urbano que permite análises ambientais e sociais, levantamento de dados (relevo, geologia, geomorfologia fauna, flora) e zoneamento dessas áreas. Contudo, os órgãos públicos não souberam ainda como operacionalizar os dados de maneira a revertê-los em ações.

Segundo o IBGE (2010), no censo demográfico de 2010 existiam, na Cidade de Macapá, 13.801 conglomerados subnormais, que são caracterizados como espaços com ocupação ilegal de terra em momento atual ou recente, com urbanização fora dos padrões vigentes refletindo em vias de circulação estreita, alimento irregular e precariedade de serviços públicos essenciais. Nestes dados também estão incluídas as áreas de ressaca do munícipio onde ocorrem as ocupações irregulares.

3 O termo “antrópica” se refere a atuação do homem na natureza. 
Figura 1 - Ocupações em áreas de ressaca em Macapá

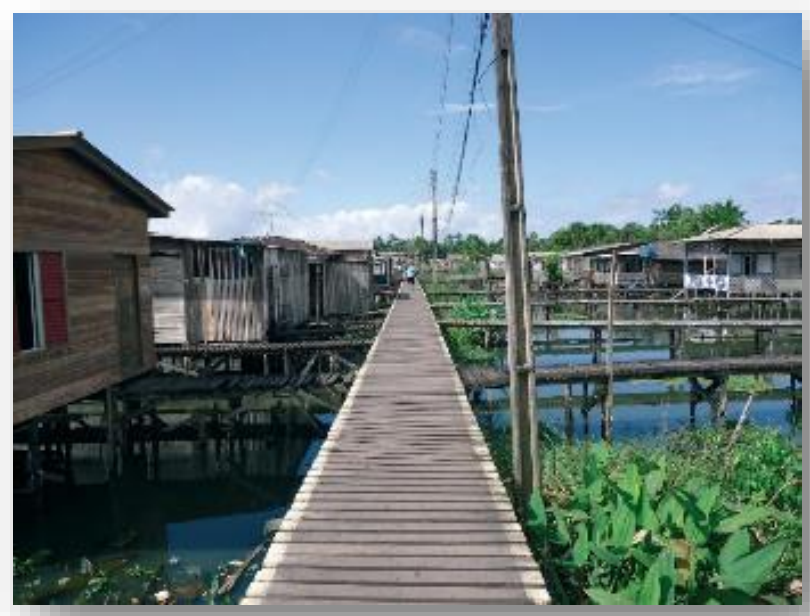

Fonte: Tribuna Amapaense, 2015.

No levantamento do Instituto de Pesquisas Científicas e Tecnológicas do Estado do Amapá (IEPA, 2012, p. 61), 74,2\% da população que reside nas áreas de ressaca são naturais do Pará, dos quais $79 \%$ vieram de regiões ribeirinhas do Pará. O tempo médio de moradia das famílias é de 11 a 16 anos, contudo, cerca de 4\% já reside a mais de 20 anos nessas localidades. $22 \%$ dessa população já teve malária ou dengue e $22 \%$ das moradias são ocupadas por mais de uma família. Estima-se que mais de $32 \%$ das margens das ressacas estão ocupadas. Ordinariamente os moradores não detém quaisquer documentos probatórios de sua posse, ainda assim, 40\% detém algum título de compra da posse que considera regular e legítimo. A população desenvolve atividades comerciais informais, principalmente vinculado as batedeiras de açaí, comercialização de pescado, estética feminina, venda de "chope" e escritório, há também serviços de alugueis de quartos e se encontram também igrejas.

Figura 2 - Área de ressaca Igarapé do Jandiá

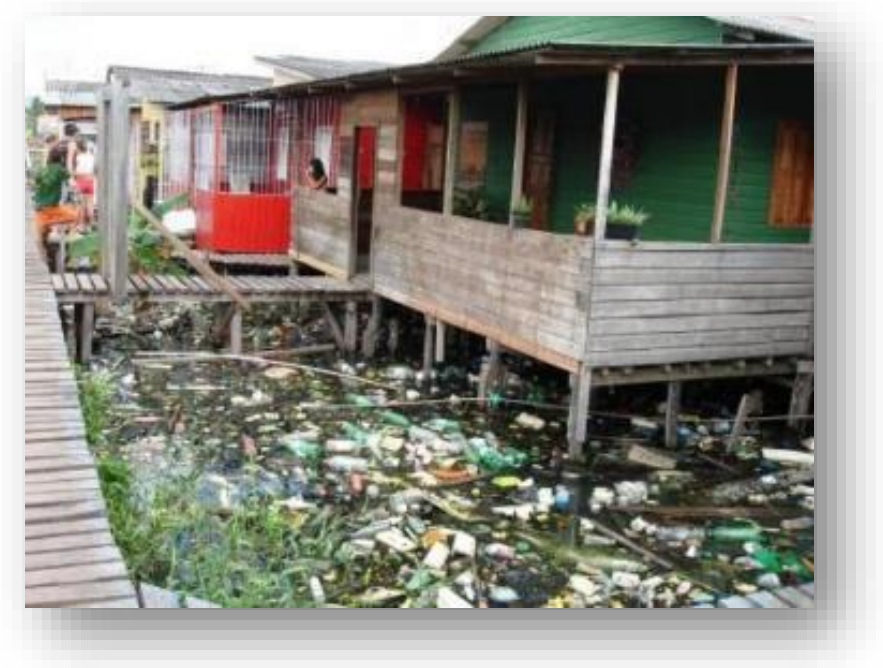

Fonte: SelesNafe.com, 2018 
Macapá é uma cidade que ainda reserva centralidade política e comercial, característicos de cidades interioranas. Embora seja uma cidade com porte populacional médio, trata-se de uma cidade horizontal, onde a construção habitacional é predominantemente de casas. A habitação vertical se eleva somente no centro em menos de uma dezena de prédios, o que faz que a cidade ocupe uma vasta área territorial.

É comum verificar nos grandes centros urbanos a predominância de áreas inapropriadas para habitação serem ocupadas, nas quais são construídas moradias fixas (muitas destas áreas são de preservação permanente), haja vista que, próximo ao centro funciona uma espécie de coração urbano, que gera e "bombeia serviços", onde se organiza o comércio e toda pulsão da vida social na cidade.

Aglomeram-se aí muitas famílias de classe baixa, fazendo revelar ausência do Estado e quaisquer modelos de plano de ação. Há forte relação entre o aumento da densidade populacional de perfil empobrecida e a não efetivação de políticas habitacionais que pensem alternativas organizacionais da cidade. As favelas aí se formam, exprimindo-se entre vielas e corredores por detrás do asfalto, ocupando espaços indesejados pelas classes mais abastada. Em Macapá, estes espaços ditos ociosos e não desejáveis são as ressacas.

Um modus operandi de ocupação do espaço vai se consolidando enquanto prática tradicionalmente reiterada, fazendo surgir modos de vivências próprias, as quais se replicam intergeracionalmente e que se expressam em estratégias informais de produção de renda. A ressaca é a cidade informal, que produz suas próprias conexões e estratégias de sobrevivência, enquanto lugar de valor de uso e de troca, onde símbolos são artesanalmente estruturados e consumidos pelos moradores.

No mapa abaixo, podemos ver em vermelho as regiões localizadas em um cinturão na volta do centro. Vale ressaltar que a zona norte foi excluída do mapa por ser zona de terra firme, onde se situam as partes mais elevadas da cidade.

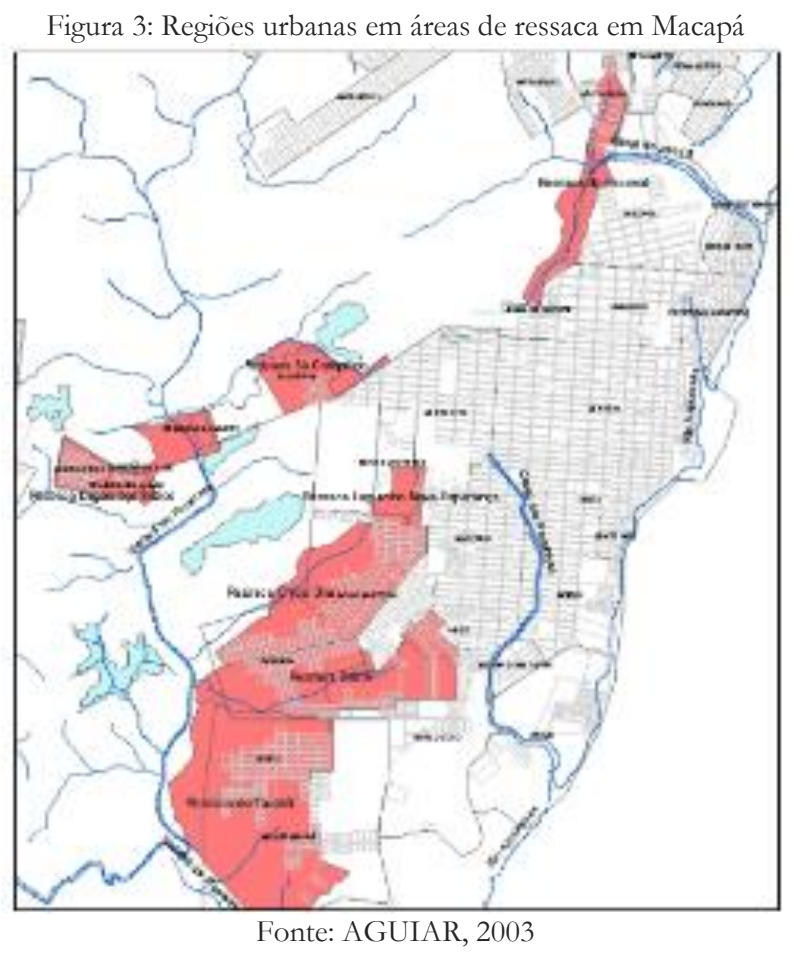


A periferia de Macapá, que é o cinturão fronteiriço da cidade com a ruralidade, contrariamente ao tipo ideal de correspondência centro-periferia e urbano-suburbano, não se aplica aqui, já que a lógica organizativa faz revelar redutos da produção de ilhotas de urbanidade, ou seja, os condomínios fechados. Os três gargalos de saída da cidade são predominantemente preenchidos com esses condomínios, seja na Zona Norte, com a construção de condomínios e bairros planejados, seja na Zona Oeste, onde aglomeram-se vários dos primeiros, e nos espaços entre o Bairro Universidade (Zona Sul) e a Fazendinha (último distrito de Macapá e fronteira com a cidade de Santana), onde vários empreendimentos destinados a classes abastadas estão em processo de desenvolvimento.

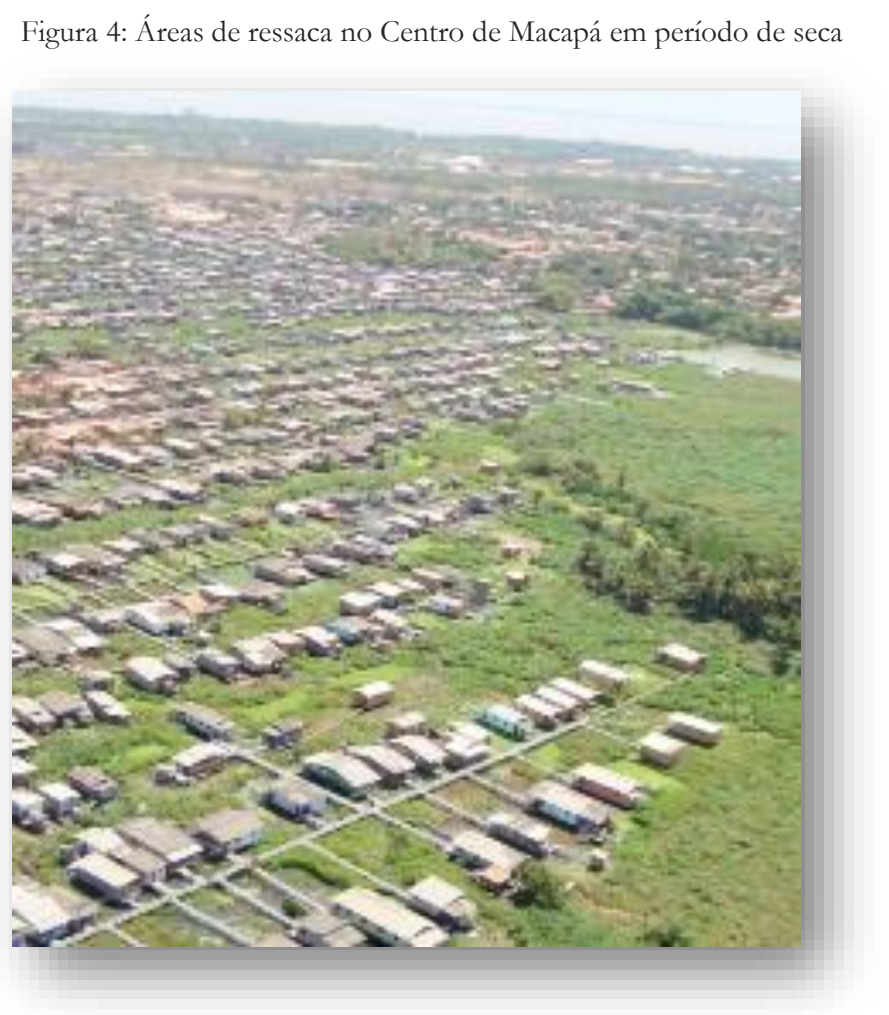

Fonte: IEPA, 2012

As áreas de ressaca em Macapá são redutos de contradição, da produção da cidade informal, onde se prolifera a suburbanidade e onde aglomeram-se as classes espoliadas dos benefícios da cidade. No entanto, tais áreas estão localizadas principalmente no entorno do centro da cidade, criando caminhos de suburbanidade na urbanidade.

\section{BIONECROPOLÍTICA4}

O termo biopolítica foi cunhado por Michel Foucault (1989) para designar a importância do fator biológico enquanto elemento central para a política, determinando-a enquanto elemento de poder. A ordenação e esquadrinhamento da população passou a ser importante para a mecânica do poder, separando pobres e ricos na anatomia das cidades, ordenando a

\footnotetext{
${ }^{4}$ Termo alcunhado a partir da interação do conceito de biopolítica e necropolítica, os quais serão explicados no decorrer deste item.
}

PRACS: Revista Eletrônica de Humanidades do Curso de Ciências Sociais da UNIFAP 
vida e suas funções. Tal necessidade se deu em face dos medos derivados da aglomeração de homens, principalmente em relação a questões de saúde pública, elemento associado ao surgimento da medicina social.

O controle da vida se dá a partir da normalização dos comportamentos, a partir de um sistema disciplinar que domestica os corpos em padrões determinados, condição para o exercício do poder sobre a cidade e o Estado. Insere-se nas estruturas de poder o esquadrinhamento, classificação e numeração sobre a vida, assim, o controle sobre o ser humano passa a ser condição do próprio poder.

Derivam daí noções impressionistas de sociedade de controle, onde o planejamento e ordenação das cidades possa ser visto como transpolítica panóptica, criando um desenho do espaço para otimizar o seu controle. A vida humana e sua distribuição topográfica passaria a ser controlada por cálculos explícitos de seus processos biológicos que transformam a vida humana. Haveria necessidade de controlar os nascimentos, mortes, fecundidade, morbidade, longevidade, migração, criminalidade, entre outras, em termos descritivos e quantificado, combinando, separando e comparando, permitindo a previsão do futuro a partir de estatísticas, demográfia, medicina social e outros saberes. Nesse sentido, podemos dizer que a biopolítica teria como pretensão maximizar a vida humana ativa e produtiva, com o fito de subtrair o máximo de tributação sobre sua produtividade para o poder.

A biopolítica ganha novos contornos no mundo contemporâneo, onde p desenho urbano ganha novas inscrições, novas demarcações, zonas, enclaves, questionamentos da propriedade, classificação de pessoas, manipulação dos recursos e de criação de novos imaginários populares (MBEMBE, 2011, p. 43).

Quando Mbembe (2011) cunha o termo necropolítica para relacionar a produção de mundos de mortes e um domínio sem precedentes da soberania de quem deve viver e morrer, esta lógica pode ser lida numa microfísica dos espaços urbanos.

Uma nova demarcação do poder cria cidades famintas não apenas de comida, como também de moradia, vestimentas, laser etc. Essa soberania, em termos foucaultinano, determina a vida/morte também determina quem é importante e quem não é, quem detém valor e quem não detém, além de determinar quem é facilmente substituível ou não, indivíduos da mesma classificação social geralmente são particionados no espaço e reunidos em enclaves específicos (MBEMBE, 2011).

A gestão do medo e do terror se materializa na produção segregativa dos seres humanos, separando ricos e pobres, a partir de zoneamentos-ilhas. A partir do exercício da soberania vertical, a classe privilegiada se apropria do espaço, determinando suas vocações e onde devem ser fortificados, visando a proteção de exclusividades. São aí criadas redes, tuneis e pontes "subterrâneos" que colonizam o poder e ratificam tais demandas nos mecanismos formais de poder.

Os esquemas subterrâneos de territorialidades determinadas são estratégias de guerra, de desarticulação do nocivo, assim a estratégia de domínio e controle estaria a se espelhar na infraestrutura, com despejos, demolições de casas, zonas e ruas. Trata-se de um modelo de ocupação colonial da modernidade presente, onde velhos sistemas de dominações se mantém retraduzidos em novos esquemas de expressão de poder ainda pautados no poder disciplinar, na biopolítica e na necropolítica (MBEMBE, 2011).

\section{RESSACAS ENQUANTO ZONAS DE SACRIFÍCIO}

PRACS: Revista Eletrônica de Humanidades do Curso de Ciências Sociais da UNIFAP https://periodicos.unifap.br/index.php/pracsISSN 1984-4352Macapá, v. 12, n. 1, p. 39-48, jan./jun. 2019 
As eleições para a prefeitura municipal de Macapá em 2016 trouxeram mais uma vez o tema do desornamento urbano para o palco dos debates. Não faltaram candidatos a apelar para o voto popular, prometendo a recuperação das passarelas, sistemas de saneamento, recolhimento de lixo, canalização de água potável etc., não raro com hologramas no horário político eleitoral, repaginando em computador essas áreas de sacrifício. No processo de "curral eleitoral" o ponto nodal caracterizou-se mais uma vez no sistema de concerto de pontes em períodos de eleição e pela tolerância institucional de zonas onde não se pagam os serviços públicos básicos, principalmente água encanada e luz, todas são estratégias do biopoder.

No que se refere a atuação da Polícia Militar, esta não adentra nas áreas de ponte e pouca atuação mantém no que se refere aos crimes que são realizados nas áreas de ressaca. A cidade informal não recebe a mesma proteção e atenção da cidade formal, o sistema de policiamento é um mecanismo de controle e contenção, o policiamento e rondas se dão no "asfalto", não adentram nas pinguelas formas de policiamento e de atuação que não seja de invasão e de crimes flagrantes.

Em verdade há um sistema de controle que só age quando a ressaca sai ao asfalto, momento que o inimigo (JAKOBS, 2008) aparece e todas as ferramentas de controle social a céu aberto são acionadas, direcionando total atenção ao cidadão nocivo e pretensamente violador da cidade olimpo.

Em verdade, os crimes no interior das áreas de ressaca a ninguém importam, pois não atingem a população da cidade formal, razão pela qual não interessa ao poder qualquer alteração na forma de atuação, já que as áreas de ressacas são reinos alternativos, onde as leis são produzidas pelo crime organizado.

O Estado passa somente na "porta" da ressaca, visando o controle e contenção daquela população dentro do seu enclave, isolando a cidade formal dos efeitos deletérios lá produzidos. Durante a semana os moradores saem para trabalhar e servir à cidade formal, enclausurada em condomínios fechados, lubrificando as engrenagens do sistema.

O poder controla e determina quem tem valor e deve ser protegido e quem não detém valor e pode ficar sujeito à criminalidade, à violência, ao medo e ao terror. Aqueles que vivem nas áreas de ressacas são trabalhadores descartáveis, pois facilmente substituíveis, e sua possível eliminação é calculada pela razão instrumental, podem ficar expostos à eliminação sem quaisquer transtornos para o poder.

Há ainda um sistema de tolerância institucionalizada do não pagamento dos serviços de água e eletricidade, pelo sistema conhecido como "gatos", o que possibilita que as palafitas que abarcam 1/3 da cidade gozem de serviços básicos sem onerar a renda das famílias pobres.

A tolerância é notória já que os postes de luz estão "no asfalto", onde dele se descolam emaranhados de fios que são distribuídos pelas palafitas. O controle institucional seria facilmente realizado, pois a fiação é artesanal e está em evidência. Soma-se ainda que os contadores de energia da companhia de energia elétrica no Estado do Amapá são instalados no poste e não nas casas. Assim, visualizam-se os postos nas entradas das áreas de ressacas desprovidos de quaisquer contadores e diversos fios em direção as residências.

Outrossim, o encanamento da companhia de distribuição de água de Macapá abastece toda a população das áreas de ressacas sem, contudo, cobrar pelos serviços prestados. Emen-

PRACS: Revista Eletrônica de Humanidades do Curso de Ciências Sociais da UNIFAP https://periodicos.unifap.br/index.php/pracsISSN 1984-4352Macapá, v. 12, n. 1, p. 39-48, jan./jun. 2019 
das nos encanamentos da empresa são realizados na entrada na ressaca e, a partir de um complexo sistema informal, são distribuídos por todas as residências. Como se tratam de áreas de alagado, a inviabilidade dos poços artesianos coloca toda a população em dependência do serviço institucional de fornecimento de água.

Josilene Cunha (2011) em sua análise dos programas institucionais de governo junto às áreas de ressaca urbana de Macapá envolve três níveis: o Programa da Melhoria da Qualidade Ambiental Urbana do Amapá GEA-BID, a saber: o nível macro (Governo Estadual), o intermediário (ONG’s) e local (comunidades do bairro da capital de Macapá), apontando diversas contradições do ponto de vista dos atores sociais e reconstituindo o contexto sociopolítico que influenciou a sua criação, assim como o mecanismo de interação entre o governo estadual e as comunidades locais e aponta os fatores que têm permitido e ou facilitado ou impedido a implementação do Programa.

\section{CONSIDERAÇÕES FINAIS}

Por esta lógica de manutenção de um mecanismo de poder que controla e regulamenta a existência de uma grande parte da população urbana de Macapá, condiciona-se um sistema de controle social a céu aberto, por uma disciplina dos serviços públicos e da regulamentação os espaços.

A tolerância da ocupação dos referidos territórios de ressaca que são, notoriamente, áreas de proteção ambiental, é um sistema de tolerância necessário para contenção e controle das massas empobrecidas que estão na cidade.

Ações técnicas como o GEA-BID e outras iniciativas macropolíticas para consorciar diretrizes urbanísticas e ambientais forçosamente necessitam da contraparte em ações e medidas que abordem os conflitos sociais, com consequente aporte de tecnologias sociais pertinentes e metodologias interdisciplinares.

Vale dizer, o contexto macropolítico das teorias de controle social - como a biopolítica foucaultiana ou a necropolítica de Mbembe - auxiliam a perceber as vulnerabilidades de populações em contextos de zonas de sacrifício e mesmo a estabelecer leituras críticas face ao Estado enquanto emanação simbólica de um poder soberano. Entretanto, não se mostram suficientes para penetrar nas redes de relações que estabelecem o exercício da sociologia de poder local, tampouco nos aspectos culturais e antropológicos que substantivam os mecanismos de resistência e as regras próprias de pertencimento.

Observar essa cosmologia implica em despir-se do teórico e penetrar o campo específico enquanto forma de aprendizado. Levando na nova bagagem as hipóteses de conceitos de APA ressemantizados, onde as habitações nas áreas de ressaca vislumbrem um modo de vida próprio e integrado às configurações naturais locais.

\section{REFERÊNCIAS}

AGUIAR, J.S. SILVA, L.M.S. Caracterização e Avaliação das Condições de Vida das Populações Residentes nas Ressacas Urbanas dos Municipios de Macapá e Santana. In: TAKIYAMA, L.R. ; SILVA, A.Q. da (orgs.). Diagnóstico das Ressacas do Estado do Amapá: Bacias do Igarapé da Fortaleza e Rio Curiaú, Macapá: CPAQ/IEPA e DGEO/SEMA, 2003. Disponível em: <www.iepa.ap.gov. $\mathrm{br} / \mathrm{metadados} /$ instituicoes/iepa/projetos/ressacas/documentos/10finalANTROPICO.pdf

PRACS: Revista Eletrônica de Humanidades do Curso de Ciências Sociais da UNIFAP https://periodicos.unifap.br/index.php/pracsISSN 1984-4352Macapá, v. 12, n. 1, p. 39-48, jan./jun. 2019 
CUNHA, Josilene Conceição Leal da. Ações de desenvolvimento socioambiental: o Programa de Melhoria da Qualidade Ambiental Urbana do Amapá GEA-BID nas áreas de ressacas da cidade de Macapá. Universidade da Amazônia: Programa de Mestrado em Desenvolvimento e Meio Ambiente Urbano, Belém PA, 2011.

FOUCAULT, Michel. Microfísica do poder, Rio de Janeiro: Editora Graal, 1989.

IEPA - INSTITUTO DE PESQUISAS CIENTÍFICAS E TECNOLÓGICAS DO ESTADO DO AMAPÁ. Projeto zoneamento ecológico econômico urbano das áreas de ressacas de Macapá e Santana, estado do Amapá: relatório técnico final. Macapá: IEPA, 2012. Disponível em: <www.mpap.mp.br/images/PRODEMAC/livros/Livro\%20Ressacas.pdf>.

INSTITUTO BRASILEIRO DE GEOGRAFIA E ESTÁTISTICAS (IBGE). Censo demográfico 2010, 2010, Disponível em: <http://cod.ibge.gov.br/6HYJ>. Acessado em: 17 de julho de 2017.

JAKOBS, Günter, MELIÁ, Manuel Cancio. Direito penal do inimigo: noções e críticas. Porto Alegre: Livraria do Advogado. $3^{a}$ ed. 2008.

LEFEBVRE, Henri. O direito à cidade, São Paulo: Editora Centauro, 2001.

MACAPÁ. Lei Complementar no 26, de 4 de fevereiro de 2014 - Institui o Plano Diretor da cidade de Macapá.

MBEMBE, Achille. Necropolítica. In: Necropolitica seguido de sobre elgobierno privado indirecto. Madrid, Espanha: Editorial Mesulina, 2011.

MP/AP - MIINISTÉRIO PÚBLICO DO AMAPÁ. Promotoria do Meio Ambiente, Clima. Disponível em: <www.mpap.mp.br/meio-ambiente/111-noticias-prodemac/192-clima>.

Ó CATÃO, Marconi do. Civilizações Urbanas e Teorias da Cidade, Revista Direito à Cidade, vol.07, no 01, 2015, p. 91-140.

RIBEIRO, Tarcyla Fidalgo, As Favelas e o Direito à Cidade: Histórico de Negação e Perspectivas para Implementação Futura. Revista Direito à Cidade, vol.05, no 01, 2013, p. 50-64.

SEMA - Secretaria de Estado de Meio Ambiente.Plano Diretor sobre ressacas, 2008

SEMPLA - Secretaria Municipal de Planejamento e Coordenação Geral. Plano Diretor de Desenvolvimento Urbano e Ambiental de Macapá. Macapá: 2004. Disponível em: <www3.macapa.ap. gov.br/arquivos/planodiretormacap/PLANO\%20DIRETOR\%20DE\%20MACAPA.pdf>, Acessado em: 30 de março de 2016.

SELESNAFE.COM. Justiça determina desocupação de entorno do Igarapé do Jandiá. "de junho de 2018. Disponível em: https://selesnafes.com/2018/06/justica-determinadesocupacao-de-entorno-do-igarape-do-jandia/.

TRIBUNA AMAPAENSE. Morar em áreas alagadas - É degradante para o homem e péssimo para o meio ambiente. 30 de julho de 2015. Disponível em: https://tribunaamapaense. blogspot.com/2015/07/morar-em-areas-alagadas-e-degradante.html 